Case Report

\title{
Acromioclavicular Dislocation Associated with Coracoid Process Fracture: Report of Two Cases and Review of the Literature
}

\author{
Ozkan Kose, ${ }^{1}$ Kerem Canbora, ${ }^{2}$ Ferhat Guler, ${ }^{1}$ Omer Faruk Kilicaslan, ${ }^{1}$ and Hasan May \\ ${ }^{1}$ Department of Orthopedics and Traumatology, Antalya Education and Research Hospital, Antalya, Turkey \\ ${ }^{2}$ Department of Orthopedics and Traumatology, Haydarpasa Numune Education and Research Hospital, Istanbul, Turkey
}

Correspondence should be addressed to Ozkan Kose; drozkankose@hotmail.com

Received 5 August 2015; Accepted 9 September 2015

Academic Editor: George Mouzopoulos

Copyright (C) 2015 Ozkan Kose et al. This is an open access article distributed under the Creative Commons Attribution License, which permits unrestricted use, distribution, and reproduction in any medium, provided the original work is properly cited.

\begin{abstract}
Acromioclavicular dislocation associated with coracoid process fracture is a rare injury. Herein we reported two further cases with such combination of injuries and reviewed all previously published cases in current literature. In this review, we discussed the demographic characteristics, mechanism of injury, diagnosis, and treatment options extensively.
\end{abstract}

\section{Introduction}

Isolated acromioclavicular (AC) joint dislocations are frequent injuries that account for approximately $9 \%$ of all shoulder girdle injuries [1]. On the other hand, AC joint dislocation associated with coracoid process $(\mathrm{CP})$ fracture is an uncommon combination of injuries. Current literature contains few numbers of published cases, and available knowledge about this rare injury comes from the published case reports. There is no extensive review of these published cases in the relevant literature. Herein, we described two more cases with AC joint dislocation associated with $\mathrm{CP}$ fracture and reviewed all previously published cases with such combination of injuries. The purpose of this review is to discuss the demographic and clinical characteristics, mechanism of injury, radiographic features, treatment options, and outcomes regarding $\mathrm{AC}$ dislocation associated with $\mathrm{CP}$ fracture in light of the current literature.

\section{Case \#1}

A 24-year-old man (worker) presented to our emergency department with left shoulder pain and deformity after he sustained a motorcycle accident. On physical examination, there was marked prominence over the AC joint which was painful with palpation. Shoulder movements were restricted and painful. Neurovascular examination revealed no abnormalities. Anteroposterior shoulder radiograph demonstrated a Type III AC joint separation with CP fracture (Figure 1(a)). As the patient was a young man who had a hard manual labor, operative treatment was decided. Under general anesthesia in beach chair position, open reduction and percutaneous $\mathrm{K}$ wire fixation was performed without additional fixation for CP fracture (Figure 1(b)). Two weeks after the operation, active pendulum exercises were started and gradually increased to full range of shoulder movements. At 5th week, the $\mathrm{K}$ wires were extracted. At the final follow-up 8 months after the initial injury, the patient was free of pain with normal shoulder movements and returned back to his previous level of activity. Final radiographs and CT showed union of CP fracture (Figure 2).

\section{Case \#2}

A 36-year-old man (electric technician) was admitted to our emergency department after he fell down from a $2 \mathrm{~m}$ height over his right shoulder. On presentation, he complained about isolated shoulder pain. There was a noticeable bump over the AC joint, the so-called the step-off sign. Active and passive shoulder movements were painful and the $\mathrm{AC}$ joint was tender on palpation. Anteroposterior shoulder Xray showed Type III AC joint dislocation and there was 


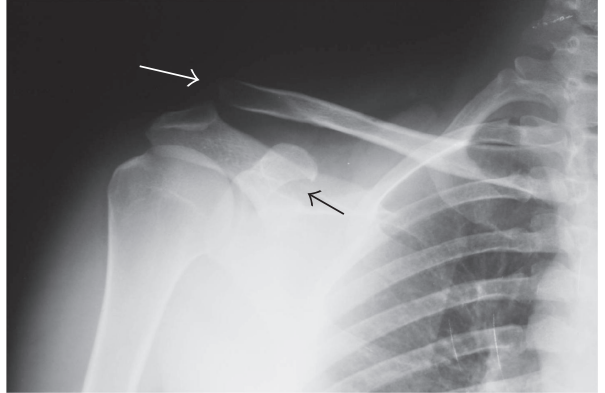

(a)

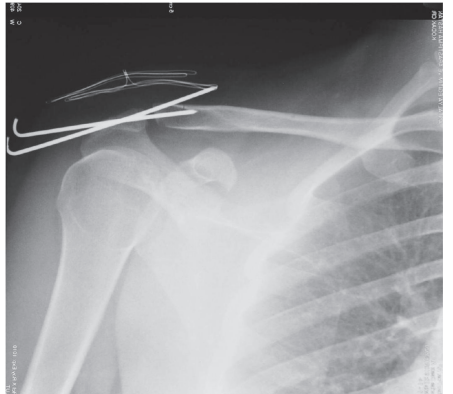

(b)

Figure 1

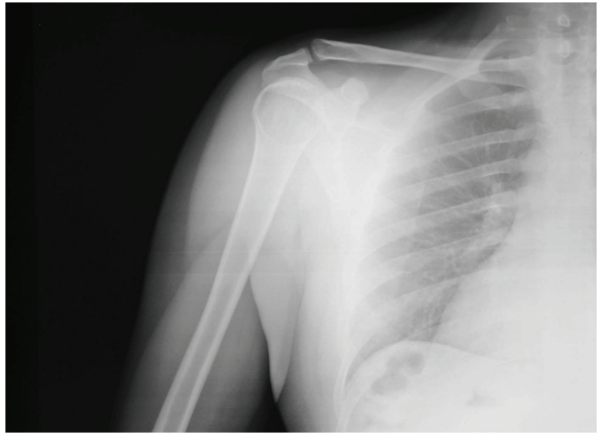

(a)

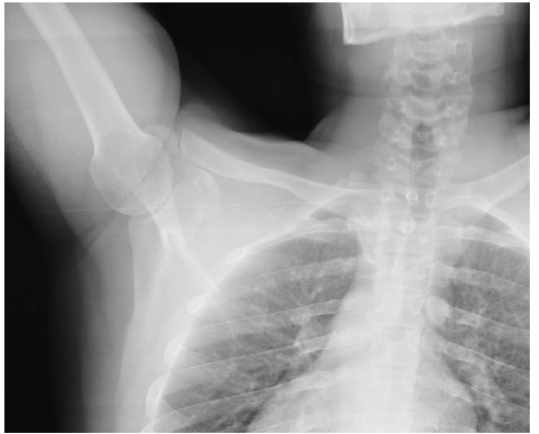

(b)

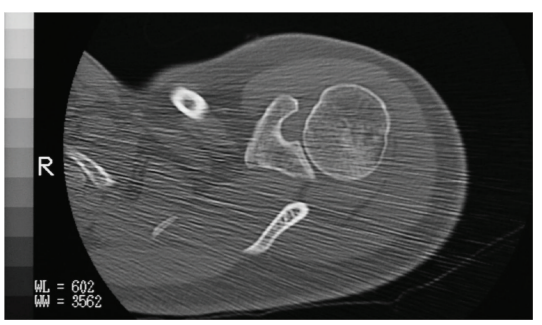

(c)

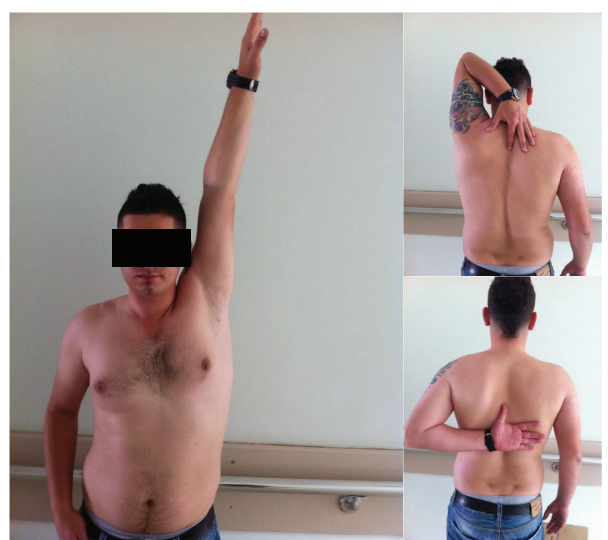

(d)

Figure 2

suspicious findings for a CP fracture (Figure 3(a)). Further $\mathrm{CT}$ imaging of the shoulder confirmed the fracture of $\mathrm{CP}$ (Figure 3(b)). As the patient had a job involving overhead activity and sustained an injury of his dominant hand, operative treatment was decided. The patient underwent open reduction and percutaneous fixation using multiple $\mathrm{K}$ wires transpassing AC joint (Figure 3(c)). No additional fixation was done to CP. The postoperative period was uneventful and the $\mathrm{K}$ wires were extracted at the 6th week. At the final follow-up 19 months after the surgery, the shoulder joint movements were full in any direction without pain. He returned to his previous level of activity and work. Final radiographs showed the proper alignment of the AC joint; however CT examination showed the nonunion of the CP fracture (Figure 4). As the patient was asymptomatic and recovered fully, no further surgery was planned.

\section{Discussion}

To the best of our knowledge, a total of 46 previous cases have been reported in the current English literature describing AC joint dislocation associated with CP fracture [2-30] (Table 1). The mean age of the reported cases (missing in three) was $25.4 \pm 14.4$ years (range, 9-77). Of these cases, $36(78.3 \%)$ were male, $7(15.2 \%)$ were female, and gender was not reported in the remaining $3(6.5 \%)$ patients. The 


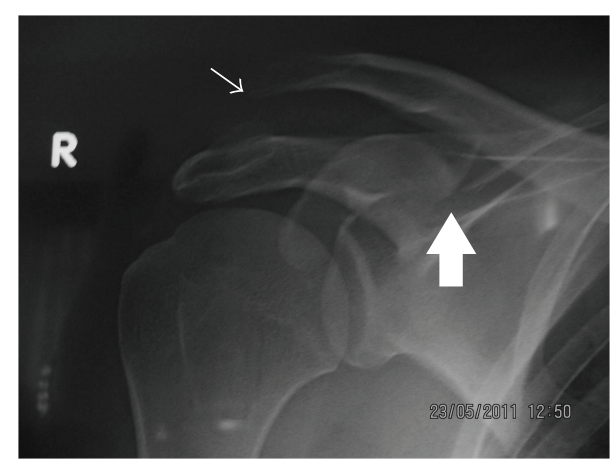

(a)

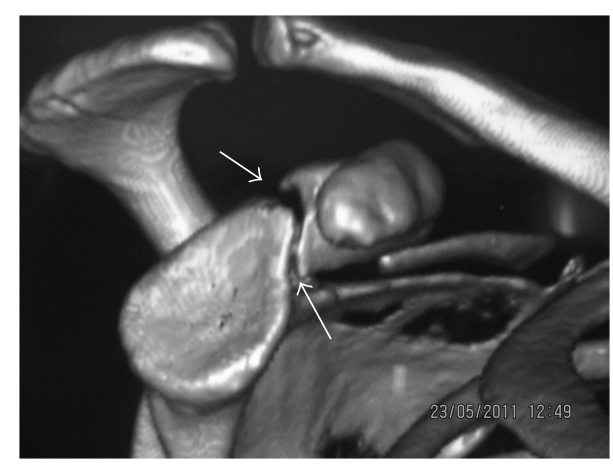

(b)

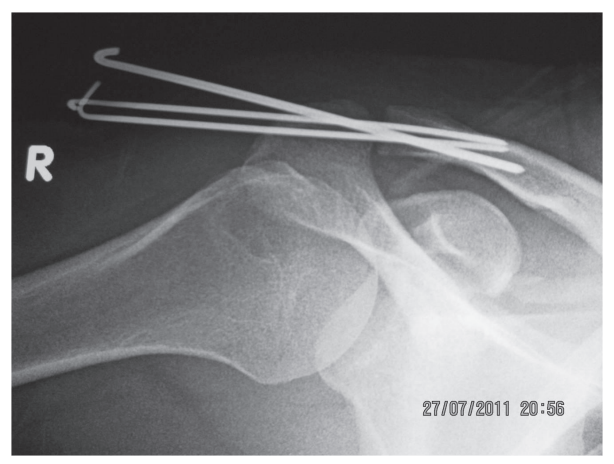

(c)

Figure 3

most common etiology was traffic accidents (16 patients, $34.8 \%)$ followed by falls $(12,26.1 \%)$ and sports trauma (12 patients, 26.1\%), respectively. These findings are consistent with the epidemiologic characteristics of the isolated AC joint dislocation in previous studies. This combined injury also is frequent in young male adults.

Two different mechanisms of injury have been proposed for $\mathrm{AC}$ dislocations $[1,16,19,25]$. The first one is direct trauma to the shoulder girdle which is usually caused by a fall or blow with the arm in the adducted position. The second mechanism is indirect trauma which occurs by falling on an adducted outstretched hand or elbow, causing the humerus to translocate superiorly, driving the humeral head into the acromion. In fact the mechanism of injury in combined AC dislocation and CP fractures is the same for isolated AC dislocations, except, instead of disrupting the CC ligaments, a fracture occurs at the coracoid, which allows for vertical displacement of the clavicle [3]. Wilson and Colwill proposed another mechanism of injury for their case and stated that forceful resisted flexion of the arm with resultant strong pull of the conjoint tendon may cause a coracoid fracture [12]. However, this theory can only explain coracoid tip fractures. In contrast, almost all cases with combination injuries had coracoid base fractures.

AC joint is a diarthrodial joint which is stabilized by surrounding strong ligaments including acromioclavicular ligaments (superior, inferior, anterior, and posterior), coracoclavicular ligaments (trapezoid and conoid), and coracoacromial ligament [1]. CP is a small hook-like structure that acts as a strong attachment point for the short head of biceps, coracobrachialis, and pectoralis minor muscles [19, $21,24,25]$. Thus relatively high energy trauma is required for combination of injuries to occur. Similarly, we have identified that almost one out of three patients (34.1\%) sustained traffic accidents.

Diagnosis of an AC dislocation is usually made with direct shoulder radiographs as the clinical findings are often evident particularly in complete AC dislocations (Type III and over), since the distance between the clavicle and CP widens and the AC joint congruity is disrupted $[1,22]$. On the other hand CP fracture may be missed due to its complex anatomic structure and superimposition on standard shoulder radiograph $[9,25]$. In case of a simultaneous injury to $\mathrm{AC}$ joint and $\mathrm{CP}$, it may be easy to miss a $\mathrm{CP}$ fracture that is overshadowed by more obvious AC dislocation [25]. A high degree of suspicion is necessary and physicians should keep in mind that these fractures can occur simultaneously. Besides standard shoulder radiographs (anteroposterior, lateral, and axillary view), special radiographic views have been described to visualize the CP better, such as Zanca view and Stryker notch view $[1,19,21,25,27]$. Zanca view is a modified anteroposterior view in which the X-ray beam is directed at the AC joint with 10-degree cephalic tilt. This eliminates the overlapping bony structure and demonstrates the AC joint better. Stryker notch view is taken when the affected extremity is placed on the top of the head and the X-ray beam is directed from anterior to posterior towards coracoid with 10 degree cephalic tilt. This projection provides a better view of 


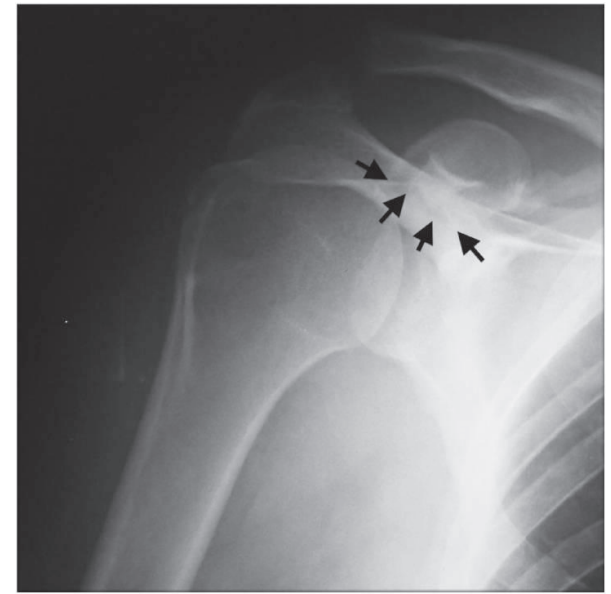

(a)

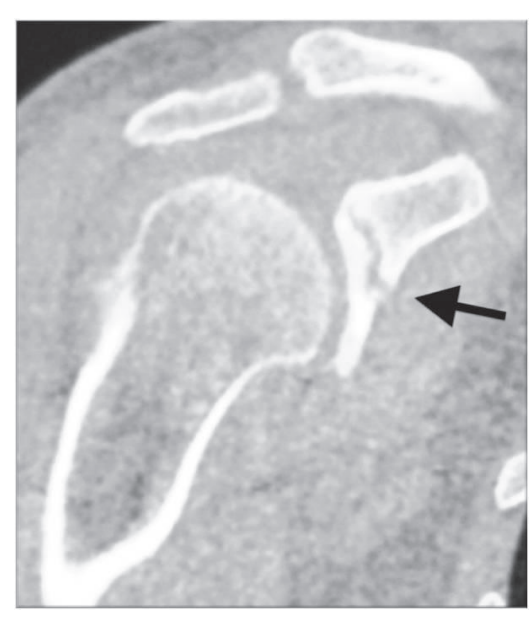

(b)

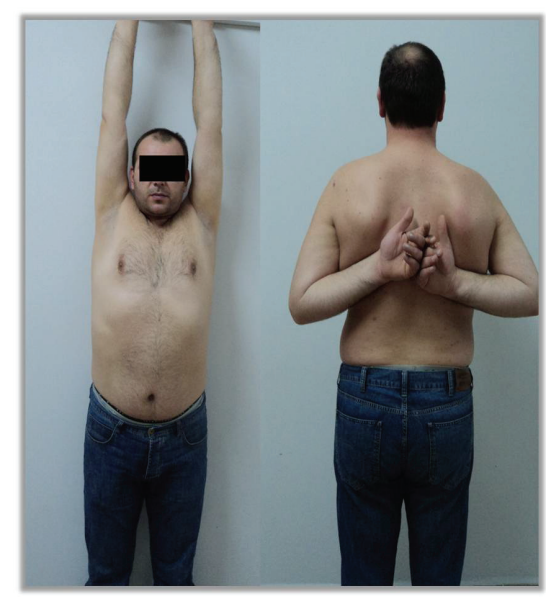

(c)

FIGURE 4

the coracoid process. However, in emergency settings, patient positioning may be difficult due to pain. In case of suspicious radiographic findings, further CT examination clearly depicts the fracture $[18,20]$. CT, particularly $3 \mathrm{D}$ reconstruction, is beneficial to realize the spatial configuration of the fracture and its extensions.

Currently there are two different classification systems for isolated CP fractures. In 1995, Eyres et al. first classified these fractures into 5 types according to the fracture location, namely, tip avulsions (1), mid-process fractures (2), basal fractures (3), superior scapula fractures (4), and fractures extending to glenoid articular surface (5) [18] (Figure 5(a)). Later on, Ogawa et al. proposed a new classification system. They divided the CP into two distinct locations based on the CC ligament attachment; namely, Type I fractures were located behind these ligaments and Type II ones were in front of them [31] (Figure 5(b)). In a combined injury AC joint and coracoids process, the fracture pattern of the coracoid is usually Type I fracture according to Ogawa and Types III and IV fracture according to Eyres et al. [18]. Traction forces mediated by CC ligaments may be the reason for this specific fracture pattern $[8,18]$.
A wide variety of treatment options have been reported for this combination of injuries ranging from conservative treatment in the form of shoulder sling [5] to complex surgical reconstructions and fixation. Treatment options can be divided into two groups either conservative treatment or surgical intervention. There is no consensus regarding the preferred treatment for these injuries and factors that contribute to the decision making process include associated injuries, patient activity level and occupation, and hand dominance. According to authors who advocate surgical treatment, this combined injury causes a double disruption of the superior shoulder suspensory complex; thus an unstable fracture which may compromise the integrity of the linkage between the clavicle and the scapula occurs $[6,16,19,22]$. Secondly, CP is a strong attachment point for several muscles. Therefore, these muscular forces may cause further displacement and motion resulting in nonunion. As a third argument, early range of motion and returning back to normal physical activities is possible with rigid fixation.

Almost half of the reported cases have been treated conservatively and result in good and excellent outcome $[2,3,7$, $9,10,13-15,17,21,26,29]$. According to our literature review, it 


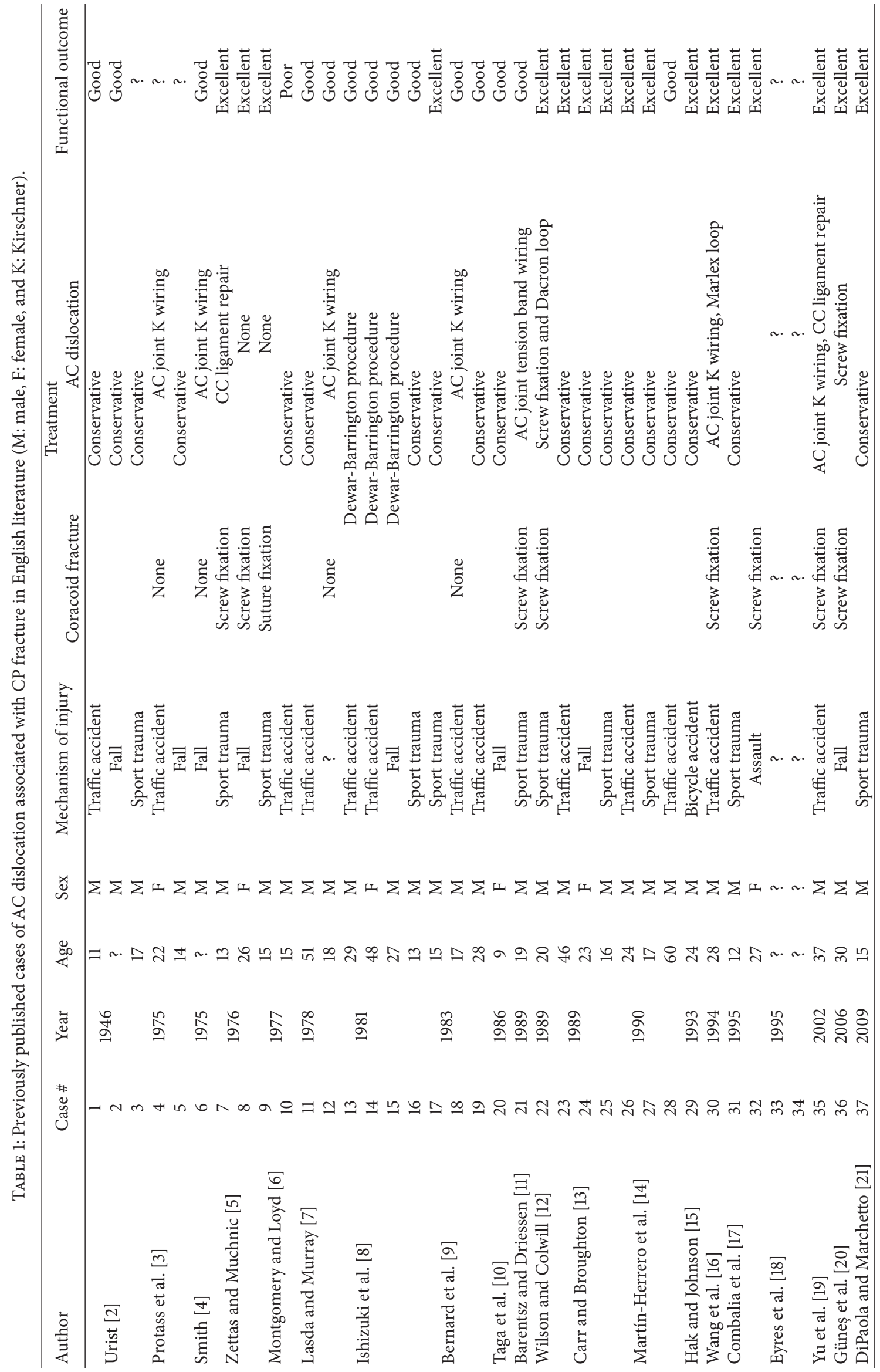




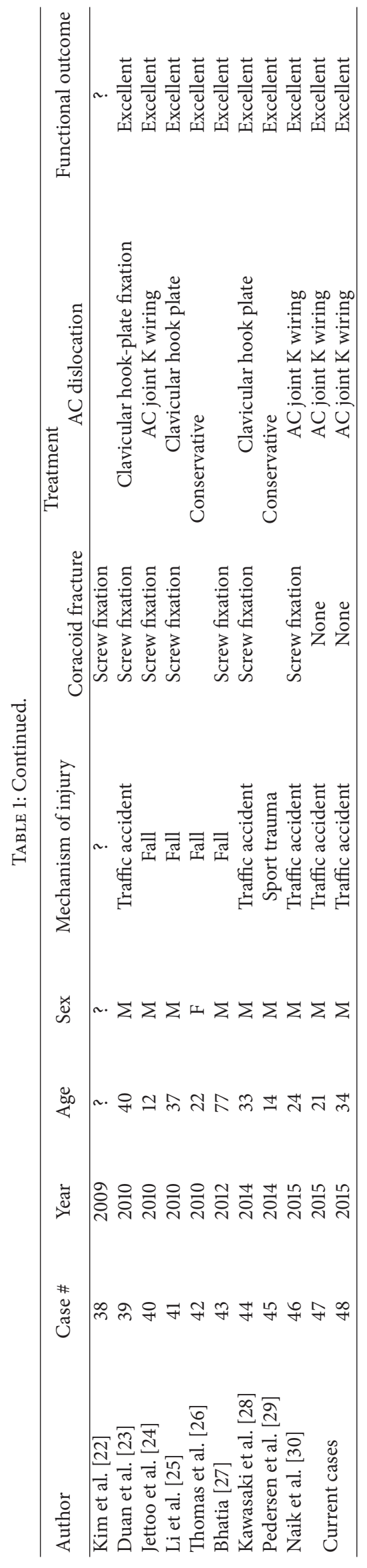




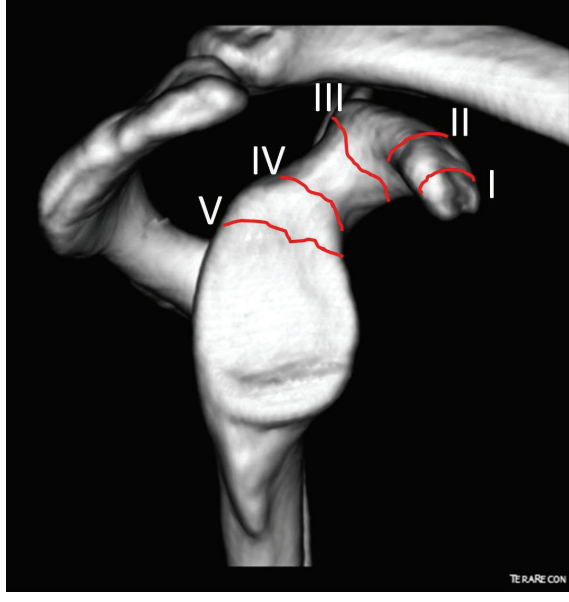

(a)

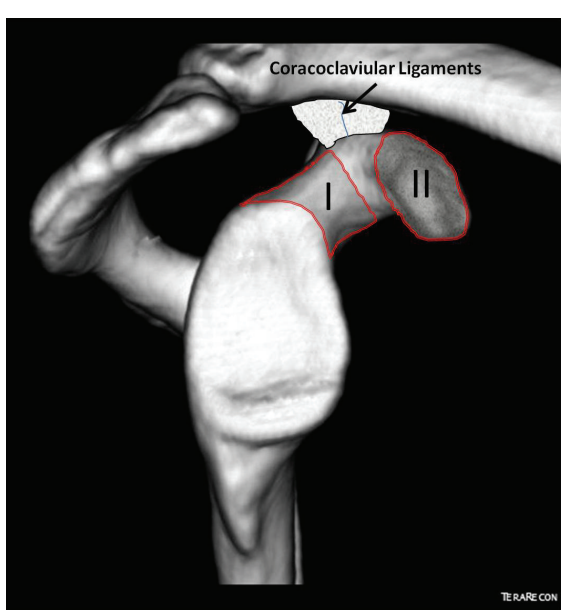

(b)

FIGURE 5

is hard to suggest best treatment option. Similarly, treatment of isolated Type III AC dislocations is still contradictory. In a recent review, there was no clear advantage of surgery over conservative treatment, and functional outcomes were similar [32]. Some authors [3, 4, 8, 9] advocated surgical fixation of only one disruption point (usually the AC joint), and some authors $[11,12,16,19,20,23-25,28]$ performed surgical intervention on both disruption points (i.e., fixation of $\mathrm{CP}$ fracture and $\mathrm{AC}$ dislocation). In our cases, we preferred surgical fixation of the AC joint only. One of our patients had pseudoarthrosis of the CP fracture at the final follow-up, although his clinical outcome was excellent.

In conclusion, AC dislocation associated with $\mathrm{CP}$ fracture is a rare injury. This combined injury is usually seen in young male adults who sustained high energy trauma. Diagnosis may be difficult on standard shoulder radiographs, and special views and/or CT can be used for definitive diagnosis in case suspicion. The treatment is still controversial; both conservative and surgical treatment methods seem to be equally effective.

\section{Ethical Approval}

All procedures performed in studies involving human participants were in accordance with the ethical standards of the 1964 Helsinki declaration and its later amendments or comparable ethical standards.

\section{Consent}

Informed consent was obtained from all patients.

\section{Conflict of Interests}

The authors declare that they have no potential conflict of interests.

\section{References}

[1] A. D. Mazzocca, R. A. Arciero, and J. Bicos, "Evaluation and treatment of acromioclavicular joint injuries," The American Journal of Sports Medicine, vol. 35, no. 2, pp. 316-329, 2007.

[2] M. R. Urist, "Complete dislocations of the acromiclavicular joint; the nature of the traumatic lesion and effective methods of treatment with an analysis of forty-one cases," The Journal of Bone and Joint Surgery, vol. 28, no. 4, pp. 813-837, 1946.

[3] J. J. Protass, F. V. Stampfli, and J. C. Osmer, "Coracoid process fracture diagnosis in acromioclavicular separation," Radiology, vol. 116, no. 1, pp. 61-64, 1975.

[4] D. M. Smith, "Coracoid fracture associated with acromioclavicular dislocation. A case report," Clinical Orthopaedics and Related Research, vol. 108, pp. 165-167, 1975.

[5] J. P. Zettas and P. D. Muchnic, "Fractures of the coracoid process base in acute acromioclavicular separation," Orthopedic Reviews, vol. 5, pp. 77-79, 1976.

[6] S. P. Montgomery and R. D. Loyd, "Avulsion fracture of the coracoid epiphysis with acromioclavicular separation. Report of two cases in adolescents and review of the literature," The Journal of Bone \& Joint Surgery-American Volume, vol. 59, no. 7, pp. 963-965, 1977.

[7] N. A. Lasda and D. G. Murray, "Fracture separation of the coracoid process associated with acromioclavicular dislocation: conservative treatment-a case report and review of the literature," Clinical Orthopaedics and Related Research, vol. 134, pp. 222-224, 1978.

[8] M. Ishizuki, I. Yamaura, Y. Isobe, K. Furuya, K. Tanabe, and Y. Nagatsuka, "Avulsion fracture of the superior border of the scapula. Report of five cases," Journal of Bone and Joint Surgery A, vol. 63, no. 5, pp. 820-822, 1981.

[9] T. N. Bernard Jr., M. E. Brunet, and R. J. Haddad Jr., "Fractured coracoid process in acromioclavicular dislocations. Report of four cases and review of the literature," Clinical Orthopaedics and Related Research, vol. 175, pp. 227-232, 1983.

[10] I. Taga, M. Yoneda, and K. Ono, "Epiphyseal separation of the coracoid process associated with acromioclavicular sprain. A case report and review of the literature," Clinical Orthopaedics and Related Research, no. 207, pp. 138-141, 1986. 
[11] J. H. Barentsz and A. P. P. M. Driessen, "Fracture of the coracoid process of the scapula with acromioclavicular separation. Case report and review of the literature," Acta Orthopaedica Belgica, vol. 55, no. 3, pp. 499-503, 1989.

[12] K. M. Wilson and J. C. Colwill, "Combined acromioclavicular dislocation with coracoclavicular ligament disruption and coracoid process fracture," The American Journal of Sports Medicine, vol. 17, no. 5, pp. 697-698, 1989.

[13] A. J. Carr and N. S. Broughton, "Acromioclavicular dislocation associated with fracture of the coracoid process," Journal of Trauma, vol. 29, no. 1, pp. 125-126, 1989.

[14] T. Martín-Herrero, C. Rodríguez-Merchán, and L. MunueraMartínez, "Fractures of the coracoid process: presentation of seven cases and review of the literature," Journal of Trauma, vol. 30, no. 12, pp. 1597-1599, 1990.

[15] D. J. Hak and E. E. Johnson, "Avulsion fracture of the coracoid associated with acromioclavicular dislocation," Journal of Orthopaedic Trauma, vol. 7, no. 4, pp. 381-383, 1993.

[16] K.-C. Wang, K.-Y. Hsu, and C.-H. Shih, "Coracoid process fracture combined with acromioclavicular dislocation and coracoclavicular ligament rupture: a case report and review of the literature," Clinical Orthopaedics and Related Research, vol. 300, pp. 120-122, 1994.

[17] A. Combalia, J. M. Arandes, X. Alemany, and R. Ramon, "Acromioclavicular dislocation with epiphyseal separation of the coracoid process: report of a case and review of the literature," Journal of Trauma: Injury, Infection and Critical Care, vol. 38 , no. 5 , pp. 812-815, 1995.

[18] K. S. Eyres, A. Brooks, and D. Stanley, "Fractures of the coracoid process," The Journal of Bone and Joint Surgery - British Volume, vol. 77, no. 3, pp. 425-428, 1995.

[19] K. S. Yu, P. T. Chan, W. K. Ngai, Y. S. Faan, and W. T. Lo, "Coracoid process fracture combined with acromioclavicular joint dislocation and coracoclavicular ligament disruption," Sicot Case-Reports, 2002, http://news.sicot.org/resources/File/ IO_reports/04-2002/2-04-2002.pdf.

[20] T. Güneş, M. Demirhan, A. Atalar, and O. Soyhan, "A case of acromioclavicular dislocation without coracoclavicular ligament rupture accompanied by coracoid process fracture," Acta Orthopaedica et Traumatologica Turcica, vol. 40, no. 4, pp. 334337, 2006.

[21] M. DiPaola and P. Marchetto, "Coracoid process fracture with acromioclavicular joint separation in an American football player: a case report and literature review," The American Journal of Orthopedics, vol. 38, no. 1, pp. 37-40, 2009.

[22] K.-C. Kim, K.-J. Rhee, H.-D. Shin, D.-K. Kim, and H.-S. Shin, "Displaced fracture of the coracoid process associated with acromioclavicular dislocation: a two-bird-one-stone solution," Journal of Trauma, vol. 67, no. 2, pp. 403-405, 2009.

[23] X. Duan, H. Zhang, H. Zhang, and Z. Wang, "Treatment of coracoid process fractures associated with acromioclavicular dislocation using clavicular hook plate and coracoid screws," Journal of Shoulder and Elbow Surgery, vol. 19, no. 2, pp. e22e25, 2010.

[24] P. Jettoo, G. de Kiewiet, and S. England, "Base of coracoid process fracture with acromioclavicular dislocation in a child," Journal of Orthopaedic Surgery and Research, vol. 5, article 77, 2010.

[25] J. Li, W. Sun, G.-D. Li, Q. Li, and Z.-D. Cai, "Fracture of the coracoid process associated with acromioclavicular dislocation: a case report," Orthopaedic Surgery, vol. 2, no. 2, pp. 165-167, 2010.
[26] K. Thomas, V. Y. Ng, and J. Bishop, "Nonoperative management of a sagittal coracoid fracture with a concomitant acromioclavicular joint separation," International Journal of Shoulder Surgery, vol. 4, no. 2, pp. 44-47, 2010.

[27] D. N. Bhatia, "Orthogonal biplanar fluoroscopy-guided percutaneous fixation of a coracoid base fracture associated with acromioclavicular joint dislocation," Techniques in Hand \& Upper Extremity Surgery, vol. 16, no. 1, pp. 56-59, 2012.

[28] Y. Kawasaki, T. Hirano, K. Miyatake, K. Fujii, and Y. Takeda, "Safety screw fixation technique in a case of coracoid base fracture with acromioclavicular dislocation and coracoid base cross-sectional size data from a computed axial tomography study," Archives of Orthopaedic and Trauma Surgery, vol. 134, no. 7, pp. 913-918, 2014.

[29] V. Pedersen, W. C. Prall, B. Ockert, and F. Haasters, "Nonoperative treatment of a fracture to the coracoid process with acromioclavicular dislocation in an adolescent," Orthopedic Reviews, vol. 6, no. 3, article 5499, 2014.

[30] M. Naik, S. K. Tripathy, S. Goyal, and S. K. Rao, "Combined acromioclavicular joint dislocation and coracoid avulsion in an adult," BMJ Case Reports, 2015.

[31] K. Ogawa, A. Yoshida, M. Takahashi, and M. Ui, "Fractures of the coracoid process," The Journal of Bone \& Joint SurgeryBritish Volume, vol. 79, no. 1, pp. 17-19, 1997.

[32] A. M. Phillips, C. Smart, and A. F. Groom, "Acromioclavicular dislocation. Conservative or surgical therapy," Clinical Orthopaedics and Related Research, vol. 353, pp. 10-17, 1998. 


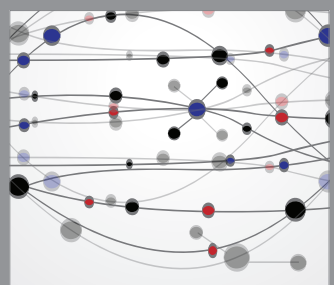

The Scientific World Journal
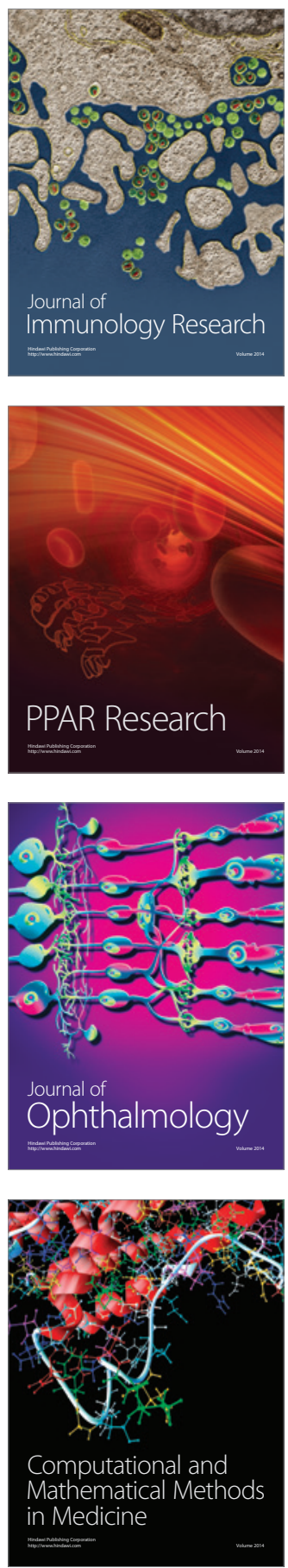

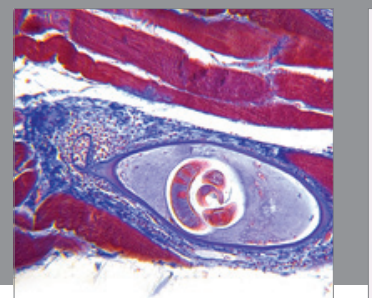

Gastroenterology

Research and Practice
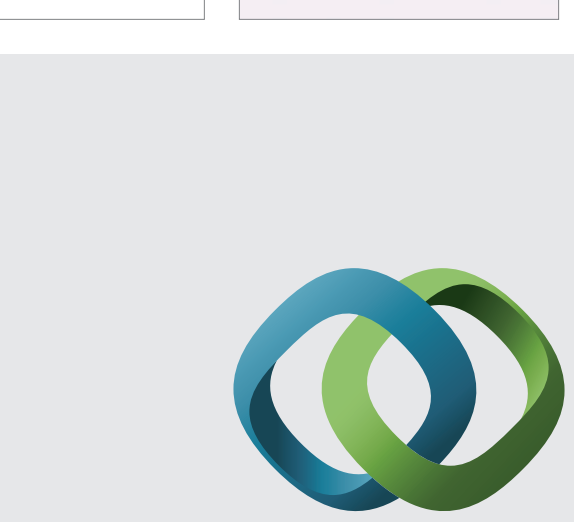

\section{Hindawi}

Submit your manuscripts at

http://www.hindawi.com
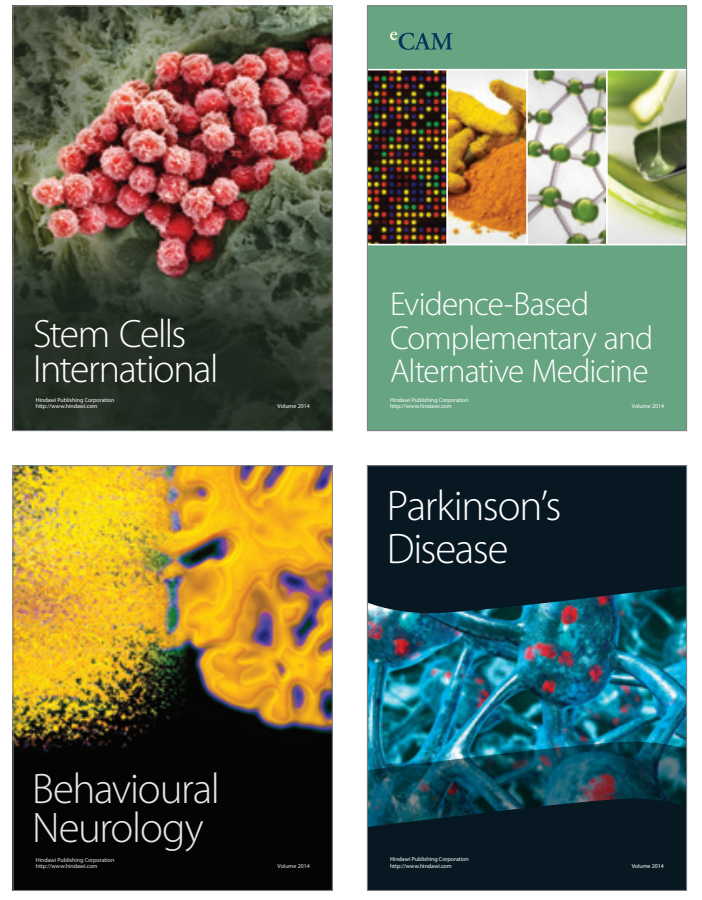
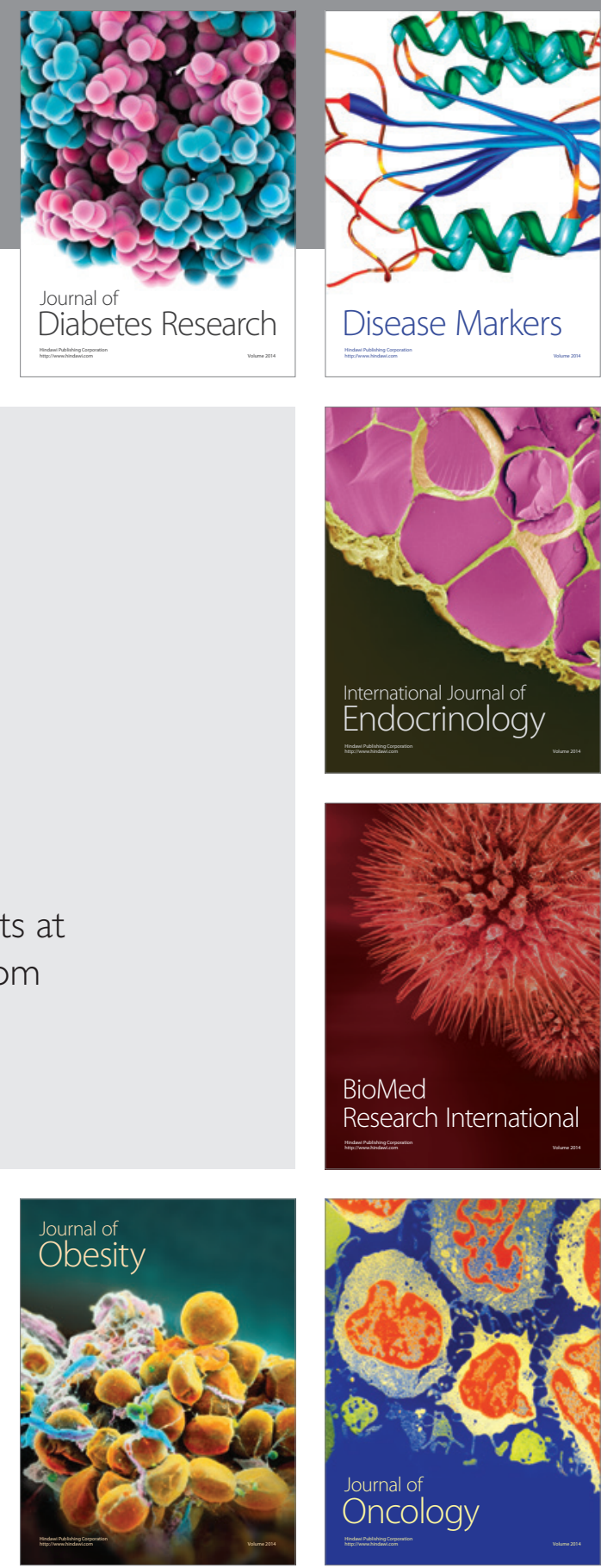

Disease Markers
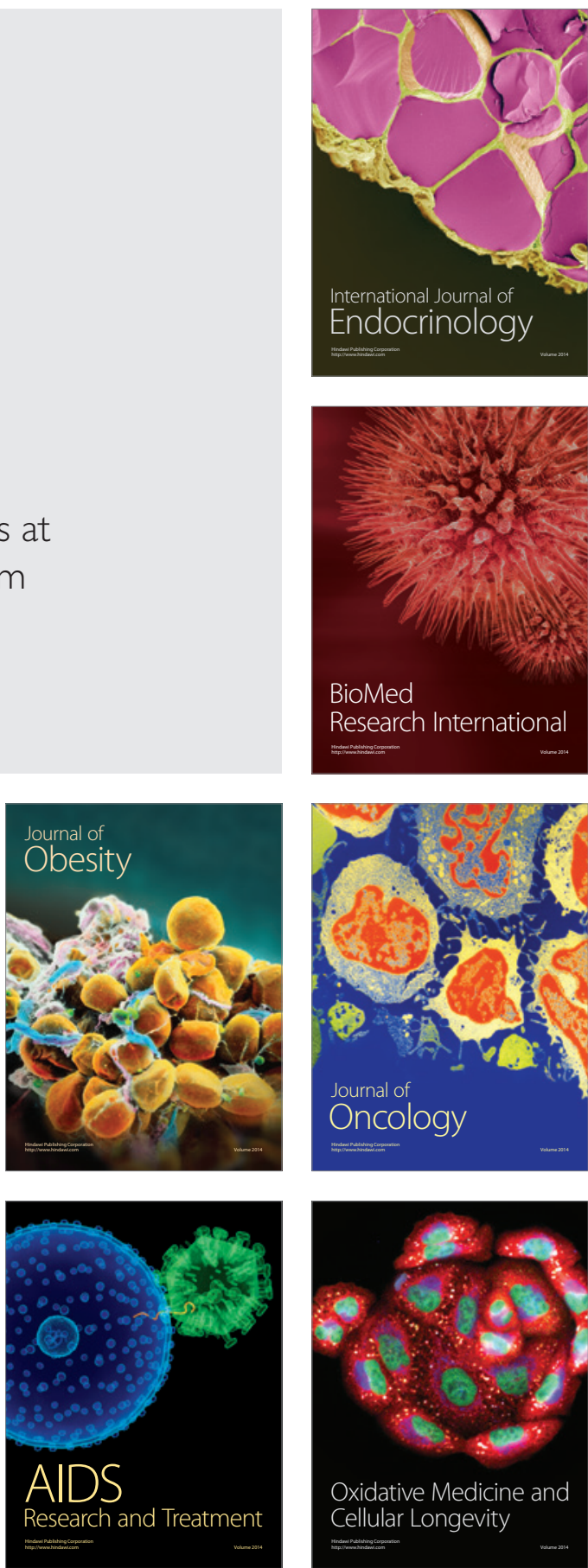